\title{
Diameter versus volumetry: a narrative review on current recommendations to measure and monitor screening detected lung nodules
}

\author{
Carlotta Sartorio, Gianluca Milanese^, Roberta Eufrasia Ledda^, Giulia Tringali, Maurizio Balbi^, \\ Francesca Milone, Nicola Sverzellati^ ${ }^{\wedge}$ Mario Silva^ \\ Scienze Radiologiche, Dipartimento di Medicina e Chirurgia (DiMeC), Università di Parma, Parma, Italy \\ Contributions: (I) Conception and design: C Sartorio, G Milanese, RE Ledda, M Silva; (II) Administrative support: G Tringali, RE Ledda; \\ (III) Provision of study materials or patients: G Tringali, F Milone; (IV) Collection and assembly of data: M Balbi; (V) Data analysis and \\ interpretation: M Silva, G Milanese, N Sverzellati; (VI) Manuscript writing: All authors; (VII) Final approval of manuscript: All authors. \\ Correspondence to: Roberta Eufrasia Ledda. Scienze Radiologiche, Pad. Barbieri, University Hospital of Parma, Via Gramsci 14, 43126 Parma, Italy. \\ Email: robertaeufrasia.ledda@unipr.it.
}

\begin{abstract}
Lung cancer (LC) is a leading cause of oncological death worldwide. Up to $70 \%$ of patients suffers from advanced disease at the time of diagnosis, which limits curative options. Early diagnosis of LC by means of low dose computed tomography (LDCT) has been proven effective by different LC screening (LCS) trials, which show a $20-30 \%$ mortality reduction in high-risk subjects. LDCT allows identification and longitudinal evaluation of pulmonary nodules (PNs), with subsequent stratification of LC risk based on their size and growth rate. Adequate management of screen-detected PN mostly relies on nodule density and sizing. Accurate size measurement is mandatory to determine the risk for malignancy, the recall rate and thus, the feasibility and the efficacy of LCS. Size and growth rate of PN can be determined by measuring either their diameter or volume. This narrative review article aims at reporting strengths and weaknesses of the two PN sizing approaches in LCS, and to discuss possible implications of PN size over- and underestimation.
\end{abstract}

Keywords: Lung cancer screening (LCS); low dose computed tomography (LDCT); pulmonary nodule (PN); diameter; volumetry

Received: 09 February 2021; Accepted: 15 June 2021; Published: 30 October 2021.

doi: $10.21037 /$ shc-21-5

View this article at: https://dx.doi.org/10.21037/shc-21-5

\section{Introduction}

Background

Lung cancer (LC) is a leading cause of death, accounting for up to $18,4 \%$ of all cancer-related deaths worldwide (1). The high mortality rate of LC is due to delay in diagnosis, with roughly $75 \%$ of cases diagnosed at advanced stages (IIIC or metastatic stage IV), limiting curative options and thus, affecting the prognosis $(1,2)$. If, indeed, the majority of patients with stage IV LC die within 5 years from the diagnosis, those with stage IA have a $>75 \%$ chance of survival over 5 years (3). Tobacco smoking represents the major risk factor for LC (4) and thus a major criterion for selection of lung cancer screening (LCS) participants. Smoking history is used in several risk models along with further integration by older age, family history of LC, and gender (5). Reduction of LC mortality by smoking cessation (also known as primary prevention) represents

^ ORCID: Gianluca Milanese, 0000-0003-1974-4854; Roberta Eufrasia Ledda, 0000-0003-3184-2676; Maurizio Balbi, 0000-0002-84363655; Nicola Sverzellati, 0000-0002-4820-3785; Mario Silva, 0000-0002-2538-7032. 
the optimal approach to control LC occurrence and further smoking related systemic diseases $(6,7)$. Unfortunately, the literature shows that smoking cessation is particularly hard to pursue (8). This is one among other reasons behind the concept of coupling primary and secondary prevention for early diagnosis (9). Early diagnosis of LC by means of low dose computed tomography (LDCT) has been proven to be effective by different LCS trials, showing a $20-30 \%$ mortality reduction in high-risk subjects $(1,10,11)$. The purpose of LCS is the detection of pulmonary nodules (PNs) harboring malignant biological behavior, representing early-stage LC candidate for curative surgery $(10,12)$.

In the last two decades, LCS trials enrolled more than 100,000 subjects, with PNs being detected in up to $66 \%$ of them (13-15). The vast majority of screen-detected $\mathrm{PN}$, however, does not represent clinically relevant lung cancers (16-18). A systematic approach to $\mathrm{PN}$ is key to limit both overdiagnosis and delayed cancer diagnosis. Safe management of screen-detected $\mathrm{PN}$ is ensured by appropriate screening intervals and adequate work-up (e.g., biopsy, positron emission tomography (PET)-CT scan). PN management mostly relies on density and size, whose accurate measurement is pivotal for several reasons: (I) to determine the risk of malignancy at baseline CT; (II) to correctly assign LDCT outcome and appropriate follow-up algorithm; and (III) to detect change in size on subsequent LDCT (19). Size and growth rate of PN can be determined by measuring either their diameter or volume. Due to its simplicity and applicability, diameter measurement has been widely used in the early phases of LCS by CT. Following the advent of thin slice CT and the availability of three dimensional segmentation software, the semi-automated volumetric approach has become a valid alternative and it is currently deemed as more accurate and reproducible (20).

\section{Objectives}

This narrative review article aims at reporting strengths and weaknesses of the two PN sizing approaches in LCS, and to discuss possible implications of PN size over- and underestimation. Future perspectives on LCS implementation within national health systems will also be discussed.

\section{Methods}

We referred to PubMed and the Cochrane database website to retrieve English-written relevant articles. Systematic reviews, meta-analyses, original articles and randomized clinical trials published up to November 2020 were considered.

We present the following article in accordance with the Narrative Review reporting checklist (available at: https:// dx.doi.org/10.21037/shc-21-5).

\section{Diameter vs, volume in LCS trials}

Although LCS trials are fairly similar in their eligibility criteria, such as age and smoking history, they differ substantially in the (I) total number of screens performed, (II) screening intervals, and (III) radiologic criteria used for PN detection and classification (Table 1) (21-24,26-31).

Management of PN relies on two main features: density and size. The density of PN differentiates between solid and sub-solid, these two categories reflect different risk profile. Size represents the most important parameter for predicting LC risk and correctly assigning LDCT outcome categories, notably in solid nodules (19). The risk of malignancy increases with nodules of greater size, being less than $1 \%$ for nodules measuring 5 to $6 \mathrm{~mm}$ and reaching up to $11.1 \%$ for those of $10-15 \mathrm{~mm}$ in diameter (32). Nodule size can be assessed by measuring either its diameter or volume $(10,33)$. For diameter measurements, $\mathrm{PN}$ are considered as twodimensional structures, whereas volumetry encompasses their three-dimensional geometry (34). According to the diameter approach, growth is called based on a fixed threshold of $2 \mathrm{~mm}$, while for the volume reference a relative increase of $25 \%$ is established for definition of actual nodule growth (35-37).

Diameter measurements are commonly used in LCS and clinical practice (38). In the NLST and several other LCS trials, maximum axial diameter was used for size determination of screen-detected PN (Table 1). Volumetry, however, is currently the recommended metric for nodule sizing, and volumetric thresholds have recently been encompassed by the Lung Imaging Reporting and Data System (LungRADS, version 1.1), whereas the previous version (issued in year 2014) only recommended the use of nodule mean diameter $(19,39)$.

\section{Diameter-based approach}

The major advantage of measuring nodule diameter is that it can be determined for all PN, regardless of their shape (regular or irregular), density (solid, part-solid or non-solid), and contact with solid structures (40). Manual measurement 
Table 1 Summary of the protocol, inclusion criteria and nodule measurement approach of the major lung cancer screening trials

\begin{tabular}{|c|c|c|c|c|c|}
\hline Screening trial & $\begin{array}{l}\text { Number of } \\
\text { participants }\end{array}$ & $\begin{array}{l}\text { Age of } \\
\text { subjects } \\
\text { (years) }\end{array}$ & Smoking history & Screening method & $\begin{array}{l}\text { Nodule assessment } \\
\text { (diameter/volume) }\end{array}$ \\
\hline DLCST (22) & 4,104 & $50-70$ & $\geq 20$ pack-years & $\begin{array}{l}\text { Baseline and annual screen by } \\
\text { LDCT for } 4 \text { years }\end{array}$ & Diameter \\
\hline MILD (23) & 4,099 & $>49$ & $\geq 20$ pack-years & $\begin{array}{l}\text { Annual or biennial screen by } \\
\text { LDCT for a median period of } \\
6 \text { years }\end{array}$ & Volume \\
\hline LUSI (26) & 4,052 & $50-69$ & $\begin{array}{l}\geq 15 \text { cigarettes per day for } \geq 25 \text { years } \\
\text { or } \geq 10 \text { cigarettes per day } \geq 30 \text { years }\end{array}$ & $\begin{array}{l}\text { Baseline and annual screen by } \\
\text { LDCT for } 4 \text { years }\end{array}$ & Diameter \\
\hline ITALUNG (27) & 3,206 & $55-69$ & $\geq 20$ pack-years & $\begin{array}{l}\text { Annual screen by LDCT for } \\
4 \text { years }\end{array}$ & Diameter \\
\hline DANTE (28) & 2,450 & $60-74$ & $\geq 20$ pack-years & $\begin{array}{l}\text { Baseline CXR and } 5 \text { annual } \\
\text { screen by either LDCT or } \\
\text { clinical review }\end{array}$ & Diameter \\
\hline
\end{tabular}

LDCT, low dose computed tomography.

of nodule diameter is commonly performed with electronic calipers, determining either the largest diameter or the average of the longest diameter and its perpendicular longest axis. This latter method is to be preferred, since PN are not necessarily spherical in shape (33). Moreover, if interand intra-observer variability is expected to range between $1.5-2 \mathrm{~mm}$ with this coupled measurement, it increases to almost $3 \mathrm{~mm}$ by using a single diameter $(41,42)$.

Regardless of the approach used, however, bidimensional measurement is affected by poor inter- and intra-observer agreement, particularly for nodules displaying irregular shape for which a proper boundaries delimitation might be difficult (43). Han et al. showed that the inter-reader variation in mean diameter of smooth and lobulated nodules was \pm 1.9 and $\pm 2.0 \mathrm{~mm}$, whereas for spiculated and irregular nodules \pm 3.4 and $\pm 4.5 \mathrm{~mm}$ (44). Numerous studies have demonstrated that such approach limits nodule sizing accuracy both at baseline (leading to different management approaches) and at subsequent screening rounds $(41,45,46)$, where small variations in size may have significant implications (e.g., an increase of $2 \mathrm{~mm}$ for a nodule of $4 \mathrm{~mm}$ at baseline represents a $50 \%$ increase). Interobserver variability can be partly controlled by measuring the diameters in the axial plane (47), but the selection of the axial slice where the nodule shows the maximum diameters represents a source of variability (45).

\section{Volume-based approach}

European LCS trials demonstrated that nodule volumetry is an accurate predictor of LC risk, associated with lower inter- and intra-observer variability as compared with 
manual bidimensional measurement $(48,49)$. Volume can be determined through a diameter-based estimation or by using automated software. Although automated volumetry carries the risk of errors, these are about 10 times smaller than those of manual measurement $(45,50,51)$. Heuvelmans et al. compared the two techniques and observed that the diameterbased approach leads to a substantial overestimation of PN volume, ranging from $47 \%$ to $85 \%$ (42). Such a discrepancy is probably due to $\mathrm{PN}$ not being perfectly spherical in shape (34). Analogously, de Margerie-Mellon et al. reported that the diameter-based assessment of nodule volume may overestimate the actual growth of pulmonary adenocarcinoma presenting as subsolid nodules (SSN) (52). Gierada et al. have recently observed how the use of semiautomated CT volumetry improved interobserver agreement and enabled classification of more PN into lower LungRADS categories than the use of either manual or semiautomated diameter measurements (48).

Although volumetry is more accurate and reproducible, volumetric software may not be available to all radiologists and its use can be rather time-consuming. Mets et al. demonstrated that only a minority of radiologists (8\%) uses volumetric software in their clinical practice (47). Different volumetry software packages (VSPs) vary in nodule size estimation. Provided that different LCS programs would not necessarily have access to the same software, Soo et al. demonstrated that nodule size thresholds for LCS recalls depend on the software used, emphasizing the need for radiologists to ensure that the VSP used in their LCS programme is comparable to those used to set guidelines (49). This variability makes the use of the same software a necessity (33).

Volumetric assessment is highly influenced by the quality of LDCT dataset. The use of thin sections and mediumsmooth or medium-sharp kernel is recommended to increase spatial resolution while reducing noise, artifacts, and partial volume effect $(53,54)$. Variability in nodule volumetry using LDCT is comparable to that of standard dose technique. Paks et al. demonstrated that all solid PN (>2 $\mathrm{mm}$ ) depicted on LDCT were detected by means of ultra-low dose CT (ULDCT) as well, and that differences in bidimensional and volume measurements were minimal between the two techniques (55).

The variability of volumetric measurement is expected to range around $25 \%$, but it increases in case of small nodules, nodules in contact with solid structures and concurrent pulmonary emphysema (33). The reproducibility of volume measurement can be affected by features unrelated to nodule size and location, such as inadequate respiratory maneuvers (e.g., expiratory acquisition increases nodule volume). Hence, providing screenees with clear instructions on how the scan apnea should be performed is essential (56).

\section{Focus on subsolid nodules}

SSN deserve special attention because of their irregular shape and density heterogeneity, which represent a challenge both for detection and measurement. SSN is defined as a nodule that does not entirely obscure the underlying vessels and bronchi; this is classified into two different subcategories: non-solid nodules (NSN, also known as ground-glass nodules) and part-solid nodules (PSNs), the latter containing both non-solid and solid components (57). Recent studies demonstrated a moderate inter- and intra-observer agreement in the classification of SSN, with discrepancy mostly caused by visual evaluation (presence and size) of the solid component (58). Most persistent PSNs harbor malignant behavior. The Early Lung Cancer Action Project (ELCAP) reported a 63\% malignancy rate among PSN, significantly higher than that of solid nodules (7\%) (59). The non-solid part usually represents either in situ or minimally invasive adenocarcinoma, whereas the solid component reflects the invasive component $(60,61)$. The use of lung widow setting, and sharp filter is recommended to accurately measure the solid component, because mediastinal window setting may lead to underestimate such component $(53,62)$.

$\mathrm{CT}$ attenuation has been proposed as a valid parameter to assess growth of SSN being the increase of solid component correlated with a rising risk for malignancy (63). Density measurement may be performed both by manual measurement and by computation of mean density and translation into mass estimate for longitudinal trajectory. Evidences, however, are still limited and larger series will be necessary to generalize preliminary results.

In PSNs, size of both the whole nodule and its solid component is an important indicator of their risk of malignancy. Detection and segmentation, however, are not easily performed on CT, especially for juxta-vascular SSN (45). The presence of vessels encompassed by the nodule can affect nodule sizing, being vessel attenuation similar to that of the solid component. To overcome this limitation, Charbonnier et al. proposed a method based on voxel classification to automatically differentiate the solid component of SSN from vessels (64). Volumetry represents an optimal tool for SSN sizing, despite some extra variability compared with solid nodules. Kamiya et al. showed that the 
volumetry of the solid component in subsolid lung cancer correlates with the risk of recurrence after surgery more than the diameter of the solid component (65).

The sensitivity of computer-aided detection (CAD) software used to be quite poor, but it currently ranges between $54 \%$ and $70 \%$, making their use safe and advisable in SSN as well as in solid nodules (66). Silva et al. compared manual and semiautomatic detection of SSN diameters in the MILD trial and demonstrated complementary performance of the two methods. Although the sensitivity of the semiautomatic approach was higher, visual confirmation was necessary to reduce the risk of false positive results (67), suggesting that the two approaches ought to be used complementarily in SSN, especially in PSN.

\section{The importance of accurate nodule sizing}

Accuracy in nodule sizing is mandatory: size overestimation might lead to unnecessary work-up, with subsequent additional LDCT recalls as well as non-invasive (e.g., PET-CT) and invasive (e.g., biopsy) work-up, whereas underestimation could result in false negative LDCT outcomes and delayed diagnosis. Of note, nodule size might also influence FDG-PET results. It has been demonstrated that uptake values are prone to underestimation for PN smaller than $8 \mathrm{~mm}$ (likely due to partial volume effects), leading to false-negative results (68). Beside size, density may affect PET-CT interpretation, causing SSN to be falsely interpreted as negative (32). Moreover, new solid nodules detected at subsequent screening rounds (incidental nodules) have a higher risk for malignancy than those detected at baseline (prevalent nodules) and should be managed more aggressively, for example by using lower volume cutoff values, which was proposed at $30 \mathrm{~mm}^{3}$ based on the NELSON trial (69).

Several factors are thought to hamper the implementation of LCS within national health systems. Among them, sustainability and cost-efficacy are the most important. Indeed, diagnostic work-up and short-term recalls result inevitably in increasing economic and psychological burden, as well as risk from biopsy or resection of a benign lesion (70-72). Notably, it has been reported a $3.4 \%$ death rate within two months after an invasive diagnostic procedure (e.g., bronchoscopy or needle biopsy) (73). Hence, limiting overdiagnosis, intended as overdetection of indolent pathology, is essential in LCS to avoid overtreatment. In NLST, the rate of overdiagnosis was $20 \%$ for screendetected cancers and $80 \%$ for screen-detected lepidic adenocarcinoma (74), showing that the risk of overdiagnosis is higher for slow growing cancers. Several strategies have been proposed to reduce the risk of overdiagnosis and overtreatment. These include the use of multidimensional stratification risk models, volume doubling time (VDT), long term active surveillance of SSN and longer screening intervals $(12,75)$. Silva et al. have recently reported that the risk of LC in LungRADS v1.1 category 1 or 2 was substantially lower than in category 3 , notably as low as $0.3 \%$ at 2 years, showing the potential for a longer than 1 year screening interval in up to $80 \%$ of NLST-eligible subjects (76).

\section{$V D T$}

Growth of a PN refers to an increase in size between two given CT examinations. Nodule growth rate is considered an independent risk factor for LC in screen-detected PN, allegedly the strongest predictor of risk (77). The optimal prediction of the likelihood of LC is granted by longitudinal assessment of VDT (33). Software-calculated VDT has a higher specificity (90\%) and sensitivity (91\%) in malignancy evaluation rather than manual caliper measurements (sensitivity 54\%) (78). VDT is expressed in days and can be calculated by using a simple exponential growth model that assumes uniform three-dimensional tumor growth, from the difference in nodule diameter (or volume) between baseline and follow-up CT, and the time interval between the two examinations (41). VDT is not meant to be calculated before three months from the previous assessment, because this can lead to either over- or underestimation of the risk for LC. As mentioned above, measurement accuracy is crucial in LCS. Even small variations in nodule sizing might result in significantly inaccurate VDT $(33,45)$.

Malignant PN tend to grow rapidly (VDT $<400$ days) but there are not strict rules. Benign PN might indeed show a rapid growth (VDT $<400$ days) as well as malignant ones might grow slowly (VDT $>400$ days) or even remain stable for a considerable period of time (77).

\section{Reporting and management recommendations}

The process of nodule work-up is based on clear communication between radiologists and other medical specialists. The use of standardized terminology prevents ambiguity and facilitates comparability of reports. Structured reporting, which ensures that all relevant findings are addressed, is highly ranked for the purpose of 
clear communication between radiologists and clinicians, in many fields of thoracic and extra-thoracic radiology $(79,80)$. Over the last two decades, several scientific societies have released PN management guidelines in order to standardize LDCT interpretation and reporting, and thus, to appropriately guide screen-detected nodule work-up (12). Among them, the most widely used are those proposed by the American College of Radiology (ACR) and the British Thoracic Society (BTS).

According to the LungRADS proposed by the ACR, $\mathrm{PN}$ are classified into different risk categories based on their size. In 2019, an updated version of LungRADS, named LungRADS v1.1, was released. The new version presents some important novelties, which reflect new evidences and advances in imaging technology. The major novelty is represented by the introduction of volume cutoff values for LungRADS categories assignment, added to diameter measurements (40). The new version also provides strict indications on how nodule measurement should be performed and recorded (e.g., long and short axis must be measured to one decimal point and the mean nodule diameter reported to one decimal point, whereas it was recommended to report the average diameterof long and short axis diameters-rounded to the nearest whole number). Other modifications are related to (I) size threshold for pure NSN, raised from 20 to $30 \mathrm{~mm}$, (II) removal of C-modifiers category (since patients diagnosed and treated for LC have annual chest CT for disease surveillance and not for screening), (III) definition of perifissural nodules, (IV) management of category 4B new large nodules developed on an annual repeat screening CT, for which one-month LDCT may be recommended to address potentially infectious or inflammatory diseases.

In 2015, the BTS released guidelines for PN investigation and management, proposing two main algorithms, based on nodule density (solid and subsolid). These two algorithms encompass both diameter and volume cutoffs for LDCT category assignment, analogously to the new version of LungRADS, but it is stated that volumetry is to be preferred as measurement method. BTS guidelines also include the use of two malignancy prediction calculators, namely Brock (also known as PanCan model) and Herder model, to better characterize the risk of malignancy $(5,35)$.

A summary of the algorithms used by the main LCS trials for management of $\mathrm{PN}$ is reported in Table 2 (21,26,27,31,36,81-83).

\section{Future perspectives}

The implementation of LCS within national health systems will inevitably lead to an increased workload. Radiologists will be expected to interpret a significant amount of LDCT, and thus to classify numerous screen-detected PN, whose adequate management relies on their sizing and characterization. This practice is highly time consuming and subjected to both intra- and inter-observer variability. In this setting, quantitative imaging (e.g., radiomics) and artificial intelligence (AI) might have a potential in LCS optimization, allowing a faster and objective LDCT evaluation (84). Ciompi et al. observed a good performance of a deep learning software in nodule classification, showing how its variability was in the same range of four experienced human observers (85). The application of such approaches may also lead to a deeper nodule characterization, revealing biological features otherwise left undiscovered. Indeed, radiomics analysis consists in the extraction of imaging features undetectable to human eyesight that might reflect nodule biological behavior (86), and that can be integrated with demographics, clinical, histologic and/or genomic data.

To conclude, the integration of $\mathrm{AI}$ and quantitative imaging techniques in LCS will likely lead to time and resources optimization, as well as to a more precise and reproducible nodule characterization, contributing to improve patients' life quality and expectancy. 
Table 2 Summary of strategies used by the LCS trials for management of solid and sub-solid nodules

\begin{tabular}{|c|c|c|}
\hline Screening trial & Indeterminate & Positive \\
\hline NELSON (36) & $\begin{array}{l}\text { Prevalent nodule } 50-500 \mathrm{~mm}^{3} \text { or incident } 15-50 \mathrm{~mm}^{3} \text { was } \\
\text { followed by LDCT after } 3 \text { months; VDT between } 400 \text { and } \\
600 \text { days was followed by annual LDCT; Incident nodule } \\
50-500 \mathrm{~mm}^{3} \text { was followed by LDCT after } 6-8 \text { weeks }\end{array}$ & Prevalent nodule $>500 \mathrm{~mm}^{3}$; VDT $<400$ days \\
\hline DLCST (22) & Nodule $5-15 \mathrm{~mm}$ followed by LDCT after 3 months & $\begin{array}{l}\text { Nodule }>15 \text { mm or suspicious morphology; } \\
\text { Growth }>25 \%\end{array}$ \\
\hline MILD (76) & $\begin{array}{l}\text { Prevalent } 60-250 \mathrm{~mm}^{3} \text { or incident nodule } 1-250 \mathrm{~mm}^{3} \text { followed } \\
\text { by LDCT after } 3 \text { months }\end{array}$ & Prevalent or incident nodule $>250 \mathrm{~mm}^{3}$ \\
\hline ITALUNG (15) & $\begin{array}{l}\text { Prevalent nodule } 5-7 \mathrm{~mm} \text { followed by LDCT after } 3 \text { months; } \\
\text { incident nodule } \leq 3 \mathrm{~mm} \text { followed by LDCT at } 6 \text { months; incident } \\
\text { nodule } 3-5 \mathrm{~mm} \text { was followed by LDCT at } 3 \text { months; incident } \\
\text { nodule }>5 \mathrm{~mm} \text { was followed by LDCT at } 1 \text { month }\end{array}$ & $\begin{array}{l}\text { Persistent } \geq 8 \mathrm{~mm} \text {; nodule growth } \geq 1 \mathrm{~mm} \text { in } \\
\text { consensus }\end{array}$ \\
\hline DANTE (82) & $\begin{array}{l}\text { Prevalent smooth } \leq 10 \mathrm{~mm} \text { or non-smooth }<6 \mathrm{~mm} \text { followed by } \\
\text { LDCT after } 3,6 \text {, and } 12 \text { months; prevalent smooth } 10-20 \mathrm{~mm} \text { or } \\
\text { non-smooth } 6-10 \mathrm{~mm} \text { followed by LDCT after } 6-8 \text { weeks }\end{array}$ & $\begin{array}{l}\text { Prevalent nodule } \geq 20 \mathrm{~mm} \text {; no regression of prevalent } \\
\text { smooth } \geq 10 \mathrm{~mm} \text { or non-smooth } 6-10 \mathrm{~mm}\end{array}$ \\
\hline
\end{tabular}

LCS, lung cancer screening; LDCT, low dose computed tomography; VDT, volume doubling time.

\section{Acknowledgments}

Funding: None.

\section{Footnote}

Provenance and Peer Review: This article was commissioned by the Guest Editors (Wieland Voigt and Helmut Prosch) for the series "Lung Cancer Screening" published in Shanghai Chest. The article has undergone external peer review.

Reporting Checklist: The authors have completed the Narrative Review reporting checklist. Available at https:// dx.doi.org/10.21037/shc-21-5

Peer Review File: Available at https://dx.doi.org/10.21037/ shc-21-5
Conflicts of Interest: The authors have completed the ICMJE uniform disclosure form (available at https:// dx.doi.org/10.21037/shc-21-5). The series "Lung Cancer Screening" was commissioned by the editorial office without any funding or sponsorship. The authors have no other conflicts of interest to declare.

Ethical Statement: The authors are accountable for all aspects of the work in ensuring that questions related to the accuracy or integrity of any part of the work are appropriately investigated and resolved.

Open Access Statement: This is an Open Access article distributed in accordance with the Creative Commons Attribution-NonCommercial-NoDerivs 4.0 International License (CC BY-NC-ND 4.0), which permits the noncommercial replication and distribution of the article with 
the strict proviso that no changes or edits are made and the original work is properly cited (including links to both the formal publication through the relevant DOI and the license). See: https://creativecommons.org/licenses/by-nc-nd/4.0/.

\section{References}

1. de Koning HJ, van der Aalst CM, de Jong PA, et al. Reduced Lung-Cancer Mortality with Volume CT Screening in a Randomized Trial. N Engl J Med 2020;382:503-13.

2. Saul EE, Guerra RB, Saul ME, et al. The challenges of implementing low-dose computed tomography for lung cancer screening in low- and middle-income countries. Nature Cancer 2020;1:1140-52.

3. Goldstraw P, Chansky K, Crowley J, et al. The IASLC Lung Cancer Staging Project: Proposals for Revision of the TNM Stage Groupings in the Forthcoming (Eighth) Edition of the TNM Classification for Lung Cancer. J Thorac Oncol 2016;11:39-51.

4. Jemal A, Bray F, Center MM, et al. Global cancer statistics. CA Cancer J Clin 2011;61:69-90.

5. McWilliams A, Tammemagi MC, Mayo JR, et al. Probability of cancer in pulmonary nodules detected on first screening CT. N Engl J Med 2013;369:910-9.

6. Jung KJ, Jeon C, Jee SH, et al. The effect of smoking on lung cancer: ethnic differences and the smoking paradox. Epidemiol Health 2016;38:e2016060.

7. Jha P, Ramasundarahettige C, Landsman V, et al. 21stcentury hazards of smoking and benefits of cessation in the United States. N Engl J Med 2013;368:341-50.

8. Rojewski AM, Tanner NT, Dai L, et al. Tobacco Dependence Predicts Higher Lung Cancer and Mortality Rates and Lower Rates of Smoking Cessation in the National Lung Screening Trial. Chest 2018;154:110-8.

9. Hoffman RM, Sanchez R, et al. Lung Cancer Screening. Med Clin North Am 2017;101:769-85.

10. Silva $M$, Pastorino U, Sverzellati N, et al. Lung cancer screening with low-dose CT in Europe: strength and weakness of diverse independent screening trials. Clin Radiol 2017;72:389-400.

11. Yip C, Tacelli N, Remy-Jardin M, et al. Imaging Tumor Response and Tumoral Heterogeneity in Non-Small Cell Lung Cancer Treated With Antiangiogenic Therapy: Comparison of the Prognostic Ability of RECIST 1.1, an Alternate Method (Crabb), and Image Heterogeneity Analysis. J Thorac Imaging 2015;30:300-7.

12. Kauczor HU, Baird AM, Blum TG, et al. ESR/ERS statement paper on lung cancer screening. Eur Radiol 2020;30:3277-94.

13. Henschke CI, McCauley DI, Yankelevitz DF, et al. Early Lung Cancer Action Project: overall design and findings from baseline screening. Lancet 1999;354:99-105.

14. Swensen SJ, Jett JR, Sloan JA, et al. Screening for lung cancer with low-dose spiral computed tomography. Am J Respir Crit Care Med 2002;165:508-13.

15. Tammemagi MC, Schmidt H, Martel S, et al. Participant selection for lung cancer screening by risk modelling (the Pan-Canadian Early Detection of Lung Cancer [PanCan] study): a single-arm, prospective study. Lancet Oncol 2017;18:1523-31.

16. Esserman LJ, Thompson IM Jr, Reid B, et al. Overdiagnosis and overtreatment in cancer: an opportunity for improvement. JAMA 2013;310:797-8.

17. Carter JL, Coletti RJ, Harris RP, et al. Quantifying and monitoring overdiagnosis in cancer screening: a systematic review of methods. BMJ 2015;350:g7773.

18. Bach PB. Overdiagnosis in lung cancer: different perspectives, definitions, implications. Thorax 2008;63:298-300.

19. Available online: https://www.acr.org/-/media/ACR/Files/ RADS/Lung-RADS/LungRADSAssessmentCategorie sv1-1.pdf?la=en

20. Han D, Heuvelmans MA, Oudkerk M, et al. Volume versus diameter assessment of small pulmonary nodules in CT lung cancer screening. Transl Lung Cancer Res 2017;6:52-61.

21. van Klaveren RJ, Oudkerk M, Prokop M, et al. Management of lung nodules detected by volume CT scanning. N Engl J Med 2009;361:2221-9.

22. Pedersen JH, Ashraf H, Dirksen A, et al. The Danish randomized lung cancer CT screening trial--overall design and results of the prevalence round. J Thorac Oncol 2009;4:608-14.

23. Pastorino U, Rossi M, Rosato V, et al. Annual or biennial CT screening versus observation in heavy smokers: 5 -year results of the MILD trial. Eur J Cancer Prev 2012;21:308-15.

24. Baldwin DR, Duffy SW, Wald NJ, et al. UK Lung Screen (UKLS) nodule management protocol: modelling of a single screen randomised controlled trial of low-dose CT screening for lung cancer. Thorax 2011;66:308-13.

25. Cassidy A, Myles JP, van Tongeren M, et al. The LLP risk model: an individual risk prediction model for lung cancer. Br J Cancer 2008;98:270-6.

26. Becker N, Motsch E, Gross ML, et al. Randomized study 
on early detection of lung cancer with MSCT in Germany: study design and results of the first screening round. J Cancer Res Clin Oncol 2012;138:1475-86.

27. Lopes Pegna A, Picozzi G, Mascalchi M, et al. Design, recruitment and baseline results of the ITALUNG trial for lung cancer screening with low-dose CT. Lung Cancer 2009;64:34-40.

28. Infante M, Lutman FR, Cavuto S, et al. Lung cancer screening with spiral CT: baseline results of the randomized DANTE trial. Lung Cancer 2008;59:355-63.

29. Blanchon T, Bréchot JM, Grenier PA, et al. Baseline results of the Depiscan study: a French randomized pilot trial of lung cancer screening comparing low dose CT scan (LDCT) and chest X-ray (CXR). Lung Cancer 2007;58:50-8.

30. National Lung Screening Trial Research Team; Aberle DR, Adams AM, et al. Reduced lung-cancer mortality with low-dose computed tomographic screening. N Engl J Med 2011;365:395-409.

31. National Lung Screening Trial Research Team; Church TR, Black WC, et al. Results of initial low-dose computed tomographic screening for lung cancer. N Engl J Med 2013;368:1980-91.

32. Elia S, Loprete S, De Stefano A, et al. Does aggressive management of solitary pulmonary nodules pay off? Breathe (Sheff) 2019;15:15-23.

33. Silva M, Milanese G, Ledda RE, et al. Screen-detected solid nodules: from detection of nodule to structured reporting. Transl Lung Cancer Res 2021;10:2335-46.

34. Petrick N, Kim HJ, Clunie D, et al. Comparison of 1D, 2D, and 3D nodule sizing methods by radiologists for spherical and complex nodules on thoracic CT phantom images. Acad Radiol 2014;21:30-40.

35. Callister ME, Baldwin DR, Akram AR, et al. British Thoracic Society guidelines for the investigation and management of pulmonary nodules. Thorax 2015;70 Suppl 2:ii1-ii54.

36. Xu DM, Gietema H, de Koning H, et al. Nodule management protocol of the NELSON randomised lung cancer screening trial. Lung Cancer 2006;54:177-84.

37. Jennings SG, Winer-Muram HT, Tarver RD, et al. Lung tumor growth: assessment with CT--comparison of diameter and cross-sectional area with volume measurements. Radiology 2004;231:866-71.

38. MacMahon H, Naidich DP, Goo JM, et al. Guidelines for Management of Incidental Pulmonary Nodules Detected on CT Images: From the Fleischner Society 2017.

Radiology 2017;284:228-43.
39. LungRADS hwaoQ-SR. Lung CT Screening Reporting and Data System (Lung-RADSTM). American College of Radiology, 2014.

40. Nishino M. CT Volumetry for Lung-RADS Classification of Solid Nodules. Radiology 2020;297:685-6.

41. Revel MP, Bissery A, Bienvenu M, et al. Are twodimensional CT measurements of small noncalcified pulmonary nodules reliable? Radiology 2004;231:453-8.

42. Heuvelmans MA, Walter JE, Vliegenthart R, et al. Disagreement of diameter and volume measurements for pulmonary nodule size estimation in CT lung cancer screening. Thorax 2018;73:779-81.

43. Bolte H, Jahnke T, Schäfer FK, et al. Interobservervariability of lung nodule volumetry considering different segmentation algorithms and observer training levels. Eur J Radiol 2007;64:285-95.

44. Han D, Heuvelmans MA, Vliegenthart R, et al. Influence of lung nodule margin on volume- and diameter-based reader variability in CT lung cancer screening. Br J Radiol 2018;91:20170405.

45. Devaraj A, van Ginneken B, Nair A, et al. Use of Volumetry for Lung Nodule Management: Theory and Practice. Radiology 2017;284:630-44.

46. Lee HN, Kim JI, Shin SY, et al. Measurement accuracy of lung nodule volumetry in a phantom study: Effect of axial-volume scan and iterative reconstruction algorithm. Medicine (Baltimore) 2020;99:e20543.

47. Mets OM, de Jong PA, Chung K, et al. Fleischner recommendations for the management of subsolid pulmonary nodules: high awareness but limited conformance - a survey study. Eur Radiol 2016;26:3840-9.

48. Gierada DS, Rydzak CE, Zei M, et al. Improved Interobserver Agreement on Lung-RADS Classification of Solid Nodules Using Semiautomated CT Volumetry. Radiology 2020;297:675-84.

49. Soo E, Edey AJ, Mak SM, et al. Impact of choice of volumetry software and nodule management guidelines on recall rates in lung cancer screening. Eur J Radiol 2019;120:108646.

50. Marten K, Auer F, Schmidt S, et al. Inadequacy of manual measurements compared to automated CT volumetry in assessment of treatment response of pulmonary metastases using RECIST criteria. Eur Radiol 2006;16:781-90.

51. Goodman LR, Gulsun M, Washington L, et al. Inherent variability of CT lung nodule measurements in vivo using semiautomated volumetric measurements. AJR Am J Roentgenol 2006;186:989-94.

52. de Margerie-Mellon C, Gill RR, Monteiro Filho AC, et 
al. Growth Assessment of Pulmonary Adenocarcinomas Manifesting as Subsolid Nodules on CT: Comparison of Diameter-Based and Volume Measurements. Acad Radiol 2020;27:1385-93

53. Bankier AA, MacMahon H, Goo JM, et al. Recommendations for Measuring Pulmonary Nodules at CT: A Statement from the Fleischner Society. Radiology 2017;285:584-600.

54. Targeted Screening for Lung Cancer with Low Radiation Dose Computed Tomography. 2019. Available online: www.england.nhs.uk

55. Paks M, Leong P, Einsiedel P, et al. Ultralow dose CT for follow-up of solid pulmonary nodules: A pilot single-center study using Bland-Altman analysis. Medicine (Baltimore) 2018;97:e12019.

56. Moser JB, Mak SM, McNulty WH, et al. The influence of inspiratory effort and emphysema on pulmonary nodule volumetry reproducibility. Clin Radiol 2017;72:925-9.

57. Godoy MC, Naidich DP. Subsolid pulmonary nodules and the spectrum of peripheral adenocarcinomas of the lung: recommended interim guidelines for assessment and management. Radiology 2009;253:606-22.

58. van Riel SJ, Sánchez CI, Bankier AA, et al. Observer Variability for Classification of Pulmonary Nodules on Low-Dose CT Images and Its Effect on Nodule Management. Radiology 2015;277:863-71.

59. Henschke CI, Yankelevitz DF, Mirtcheva R, et al. CT screening for lung cancer: frequency and significance of part-solid and nonsolid nodules. AJR Am J Roentgenol 2002;178:1053-7.

60. Revel MP. Avoiding overdiagnosis in lung cancer screening: the volume doubling time strategy. Eur Respir J 2013;42:1459-63.

61. Lee KH, Goo JM, Park SJ, et al. Correlation between the size of the solid component on thin-section CT and the invasive component on pathology in small lung adenocarcinomas manifesting as ground-glass nodules. J Thorac Oncol 2014;9:74-82.

62. Yoo RE, Goo JM, Hwang EJ, et al. Retrospective assessment of interobserver agreement and accuracy in classifications and measurements in subsolid nodules with solid components less than $8 \mathrm{~mm}$ : which window setting is better? Eur Radiol 2017;27:1369-76.

63. Zhang L, Yankelevitz DF, Carter D, et al. Internal growth of nonsolid lung nodules: radiologic-pathologic correlation. Radiology 2012;263:279-86.

64. Charbonnier JP, Chung K, Scholten ET, et al. Automatic segmentation of the solid core and enclosed vessels in subsolid pulmonary nodules. Sci Rep 2018;8:646.

65. Kamiya S, Iwano S, Umakoshi H, et al. Computer-aided Volumetry of Part-Solid Lung Cancers by Using CT: Solid Component Size Predicts Prognosis. Radiology 2018;287:1030-40.

66. Silva M, Milanese G, Seletti V, et al. Pulmonary quantitative CT imaging in focal and diffuse disease: current research and clinical applications. Br J Radiol 2018;91:20170644.

67. Silva M, Schaefer-Prokop CM, Jacobs C, et al. Detection of Subsolid Nodules in Lung Cancer Screening: Complementary Sensitivity of Visual Reading and Computer-Aided Diagnosis. Invest Radiol 2018;53:441-9.

68. Tang K, Wang L, Lin J, et al. The value of 18F-FDG PET/CT in the diagnosis of different size of solitary pulmonary nodules. Medicine (Baltimore) 2019;98:e14813.

69. Walter JE, Heuvelmans MA, de Jong PA, et al. Occurrence and lung cancer probability of new solid nodules at incidence screening with low-dose CT: analysis of data from the randomised, controlled NELSON trial. Lancet Oncol 2016;17:907-16.

70. Oudkerk M, Devaraj A, Vliegenthart R, et al. European position statement on lung cancer screening. Lancet Oncol 2017;18:e754-66.

71. Wu GX, Raz DJ, Brown L, et al. Psychological Burden Associated With Lung Cancer Screening: A Systematic Review. Clin Lung Cancer 2016;17:315-24.

72. Humphrey LL, Deffebach M, Pappas M, et al. Screening for lung cancer with low-dose computed tomography: a systematic review to update the US Preventive services task force recommendation. Ann Intern Med 2013;159:411-20.

73. Bach PB, Mirkin JN, Oliver TK, et al. Benefits and harms of CT screening for lung cancer: a systematic review. JAMA 2012;307:2418-29.

74. Patz EF Jr, Pinsky P, Gatsonis C, et al. Overdiagnosis in low-dose computed tomography screening for lung cancer. JAMA Intern Med 2014;174:269-74.

75. Silva M, Prokop M, Jacobs C, et al. Long-Term Active Surveillance of Screening Detected Subsolid Nodules is a Safe Strategy to Reduce Overtreatment. J Thorac Oncol 2018;13:1454-63.

76. Silva M, Milanese G, Sestini S, et al. Lung cancer screening by nodule volume in Lung-RADS v1.1: negative baseline CT yields potential for increased screening interval. Eur Radiol 2021;31:1956-68.

77. Zhang R, Tian P, Qiu Z, et al. The growth feature and its diagnostic value for benign and malignant pulmonary 
nodules met in routine clinical practice. J Thorac Dis 2020;12:2019-30.

78. Revel MP, Merlin A, Peyrard S, et al. Software volumetric evaluation of doubling times for differentiating benign versus malignant pulmonary nodules. AJR Am J Roentgenol 2006;187:135-42.

79. Rubin DL. Creating and curating a terminology for radiology: ontology modeling and analysis. J Digit Imaging 2008;21:355-62.

80. Sverzellati N, Odone A, Silva M, et al. Structured reporting for fibrosing lung disease: a model shared by radiologist and pulmonologist. Radiol Med 2018;123:245-53.

81. Field JK, Duffy SW, Devaraj A, et al. Implementation planning for lung cancer screening: five major challenges. Lancet Respir Med 2016;4:685-7.

82. Infante M, Cavuto S, Lutman FR, et al. A randomized

doi: $10.21037 /$ shc-21-5

Cite this article as: Sartorio C, Milanese G, Ledda RE, Tringali G, Balbi M, Milone F, Sverzellati N, Silva M. Diameter versus volumetry: a narrative review on current recommendations to measure and monitor screening detected lung nodules. Shanghai Chest 2021;5:39. study of lung cancer screening with spiral computed tomography: three-year results from the DANTE trial. Am J Respir Crit Care Med 2009;180:445-53.

83. Sverzellati N, Silva M, Calareso G, et al. Low-dose computed tomography for lung cancer screening: comparison of performance between annual and biennial screen. Eur Radiol 2016;26:3821-9.

84. Ather S, Kadir T, Gleeson F, et al. Artificial intelligence and radiomics in pulmonary nodule management: current status and future applications. Clin Radiol 2020;75:13-9.

85. Ciompi F, Chung K, van Riel SJ, et al. Towards automatic pulmonary nodule management in lung cancer screening with deep learning. Sci Rep 2017;7:46479.

86. Gillies RJ, Kinahan PE, Hricak H, et al. Radiomics: Images Are More than Pictures, They Are Data. Radiology 2016;278:563-77. 